\title{
PROPORCIONALIDADE NO SUPREMO: UMA IDEIA FORA DO LUGAR $^{1}$
}

\section{PROPORTIONALITY IN BRAZILIAN SUPREME COURT: A MISPLACED IDEA}

\author{
RAFAEL BELLEM DE LIMA²
}

RESUMO: A proporcionalidade ganhou destaque, nas últimas décadas, como uma das principais técnicas de argumentação no direito constitucional. Desenvolvido na Alemanha, este método estruturado de fundamentação de decisões sobre a admissibilidade de restrições a direitos constitucionais difundiu-se amplamente escala global. Embora a concepção e disseminação internacional da proporcionalidade possam ser justificadas pela sua potencial contribuição para o processo de justificação da atividade estatal por meio do controle judicial, no Brasil, o recurso a esta técnica tem sido criticado por provocar consequências opostas. Ao recorrer à proporcionalidade como uma ferramenta retórica, distorcendo sua estrutura e suas exigências argumentativas a fim de conferir uma pretensa sofisticação teórica e legitimar suas posições individuais, os Ministros Supremo Tribunal Federal contribuem para esse fenômeno de reprodução imprópria de uma ideia estrangeira com consequências nocivas para o direito brasileiro.

Palavras-Chave: Proporcionalidade; Argumentação jurídica; Controle de Constitucionalidade; Supremo Tribunal Federal.

\footnotetext{
${ }^{1}$ Agradeço ao assessor externo ad-hoc da FAPESP - Fundação de Amparo à Pesquisa do Estado de São Paulo, que, em parecer anônimo sobre o relatório parcial da minha pesquisa de doutorado, questionou se a proporcionalidade não seria uma ideia fora de lugar. Sou grato a Virgílio Afonso da Silva e Robert Alexy, que orientaram a pesquisa de doutorado que deu origem a esse trabalho, à FAPESP e ao programa conjunto de bolsas de doutorado na Alemanha - DAAD, Capes e CNPq, que a financiaram. Agradeço também a Diego Werneck Arguelhes e Natália Pires de Vasconcelos pelas valiosas críticas, sugestões e comentários a este texto.

2 Doutorando em Direito pela Christian-Albrechts Universität zu Kiel (Alemanha) e pela Universidade de São Paulo (dupla-titulação). Mestre em Direito do Estado pela Faculdade de Direito da Universidade de São Paulo. Professor em tempo integral do Insper - Instituto de Ensino e Pesquisa. E-mail: rafaelsbl@insper.edu.br.
} 
ABSTRACT: In the last decades, proportionality has emerged as one of the main frameworks for assessing constitutional rights' violations. Developed in Germany, this method has spread widely and on a global scale. Although conceived and disseminated under the claim that it can possibly help both the state and courts with their justification processes, proportionality has been criticized in Brazil for having the opposite consequence. The Brazilian Federal Supreme Court adopts proportionality as a rhetorical tool, distorting its structure and its argumentative requirements in the name of a supposed theoretical sophistication and to legitimize individual positions of justices. This improper reproduction of a foreign idea has harmful consequences for Brazilian law.

KEYWORDS: Proportionality; Legal reasoning; Constitutional review; Brazilian Federal Supreme Court.

Ao longo de sua reprodução social, incansavelmente o Brasil põe e repõe ideias europeias, sempre em sentido impróprio. É nesta qualidade que elas serão matéria e problema para a literatura. (Robert Schwarz, As ideias fora do lugar)

\section{INTRODUÇÃO}

Nas últimas décadas, proporcionalidade tornou-se um termo de uso corrente no discurso jurídico, sobretudo no âmbito do direito constitucional. Como notam diversos autores, esta técnica de argumentação desenvolvida na Alemanha disseminou-se rapidamente em escala global, chegando a ser considerada o expoente mais bem-sucedido de um processo de migração de ideias constitucionais e, talvez com um certo exagero, de um modelo global de direito constitucional. ${ }^{3}$ Este método passou a ser adotado até mesmo no Reino Unido, onde, em respeito ao sedimentado princípio da soberania do parlamento, os atos emanados do Poder Legislativo britânico não podem ser invalidados pelos órgãos judiciais, nem mesmo quando são considerados incompatíveis com normas de direitos fundamentais. ${ }^{4}$

\footnotetext{
${ }^{3}$ Cf. Cohen-Eliya e Porat (2013, p. 2), Möller (2012, p. 13), Stone-Sweet e Matthews (2009, p. 173). Tamanha é a relevância da proporcionalidade no direito contemporâneo, que Grant Huscroft, Bradley W. Miller e Grégoire Webber (2014, p. 01) chegam a afirmar que: "To speak of human rights is to speak of proportionality".

${ }^{4}$ De acordo com as nas seções 3 e 4 do Human Rights Act, os atos parlamentares devem ser interpretados de a modo a evitar violações a direitos fundamentais "so far as it is possible to do so" e, quando isso não for possível, devem ser declarados incompatíveis com a Convenção Europeia dos Direitos Humanos. Nessa hipótese, a decisão sobre a perda da validade das medidas
} 
Além da Alemanha e do Reino Unido, a utilização do exame de proporcionalidade no controle de medidas estatais que restringem direitos fundamentais também pode ser observada por toda Europa, inclusive em países do leste europeu, Américas do Sul e Central, África do Sul, Israel, Índia, Coreia do Sul, Nova Zelândia e Canadá, bem como em tribunais supranacionais, como a Corte Europeia de Justiça, a Corte Europeia de Direitos Humanos, a Corte Interamericana de Direitos Humanos e a Organização Mundial do Comércio (MATHEWS; STONESWEET, 2011, p. 699-785; MÖLLER, 2014, p. 380-381; COHEN-ELIYA, PORAT, 2013, p. 465; HUSCROFT, MILLER, WEBER, 2014, p. 1; CLÉRICO, 2012, p. 201-202). Mesmo nos Estados Unidos da América, que é notoriamente reconhecido como a maior exceção a este fenômeno ${ }^{5}$, há quem aponte a existência de alguns traços marcantes deste paradigma global de interpretação constitucional, seja na prática recente (MÖLLER, 2012, p. 17-20) ou momentos anteriores da jurisprudência constitucional, sobretudo na Corte Warren. ${ }^{6}$

O Brasil não é exceção a esse cenário. Nos últimos vinte anos, as menções à proporcionalidade e suas três sub-regras - adequação, necessidade e proporcionalidade em sentido estrito - têm sido frequentes tanto na literatura jurídica, como na prática forense brasileira. Um dos maiores símbolos da expressiva popularização da proporcionalidade no Brasil foi a sua previsão, no Código de Processo Civil de 2015, como um dos elementos que devem ser observados na aplicação do direito, ao lado de noções basilares do sistema jurídico nacional, inclusive já consagradas constitucionalmente, como a legalidade, a publicidade e a eficiência. ${ }^{7}$ Seja por meio de seus votos ou de suas publicações acadêmicas, os

incompatíveis compete, no entanto, ao próprio Parlamento. Para uma análise detalhada sobre estas duas hipóteses, cf. Kavanagh (2009, p. 19-164).

${ }^{5}$ Frederick Schauer (2005, p. 55) contropõe o que chama de "American approach" ao "non-American approach" e Lorraine Weinrib (2006, p. 93), a "indigenous historically based constitutional conception" norte-americana ao "rights-based postwar paradigm" adotado no resto do mundo.

${ }^{6}$ Apesar de reconhecer o excepcionalismo norte-americano, Weinrib (2006, p. 93-111) entende que houve momentos na história constitucional norte-americana, sobretudo durante a corte Warren, em que a Suprema Corte norte-americana apresentou uma postura distinta, muito mais próxima do paradigma de interpretação constitucional dominante no restante do mundo no pós-guerra. No mesmo sentido Mathews e Stone-Sweet (2011) e Huscroft, Miller e Weber (2014). Cohen-Eliya e Porat (2010, p. 276-284) também reconhecem estes momentos em que elementos muito semelhantes ao sopesamento e à proporcionalidade foram centrais para o direito constitucional norte-americano. prática constitucional norte-americana. Entretanto, no entendimento desses autores, isto ocorreu em um contexto histórico muito peculiar, de reação ao formalismo e à ideologia excessivamente liberal (libertarian) da era Lochner, o que explicaria tanto a sua efemeridade quanto a atual resistência ao sopesamento e à proporcionalidade no direito norteamericano.

${ }^{7}$ Cf. "Art. $8^{\circ}$ Ao aplicar o ordenamento jurídico, o juiz atenderá aos fins sociais e às exigências do bem comum, resguardando e promovendo a dignidade da pessoa humana e observando a proporcionalidade, a razoabilidade, a legalidade, a publicidade e a eficiência" (BRASIL, 2015) 
ministros do Supremo Tribunal Federal tiveram uma contribuição significativa para esse fenômeno.

Neste ensaio, argumentarei que o recurso à proporcionalidade na jurisprudência do Supremo Tribunal Federal tem cumprido um propósito fundamentalmente distinto daquele que orientou o desenvolvimento desse método e, principalmente, daquele que poderia justificar a sua utilização na jurisdição constitucional. Ao invés de impor ônus argumentativos claros e bem definidos para a superação de medidas que restringiriam de modo injustificável as garantias constitucionais, canalizando a argumentação jurídica para considerações sobre direitos fundamentais, na jurisprudência do Supremo Tribunal Federal, a proporcionalidade tem sido utilizada como um artifício retórico. Sua invocação não parece cumprir nenhuma outra função além de conferir uma pretensa sofisticação teórica à posição encampada pelo ministro e, dessa forma, aumentar o seu poder de convencimento.

Essa utilização meramente retórica da proporcionalidade faz jus a críticas não apenas pela impropriedade na reprodução de uma técnica desenvolvida no exterior. Além do sincretismo metodológico e das impropriedades teóricas e conceituais, que já têm sido apontadas na literatura, a forma por meio da qual a proporcionalidade vem sendo utilizada pelo Supremo Tribunal Federal em nada contribui para que a corte atue como instância de justificação da atividade estatal. Ao contrário do que fazem crer as citações à ideia de representação argumentativa da população por meio das cortes constitucionais, que têm aparecido em votos e manifestações de ministros do STF, o uso retórico e impreciso da proporcionalidade na motivação de decisões tende, na verdade, a comprometer a legitimidade democrática da jurisdição constitucional no Brasil.

\section{UMA FERRAMENTA PARA CONTROLE DE DECISÕES}

Apesar da controvérsia quanto à sua classificação como princípio, regra, máxima ou postulado, a proporcionalidade pode ser definida como uma estrutura de argumentação utilizada para fundamentar decisões sobre a manutenção ou a revisão de atos, especialmente estatais ${ }^{8}$, que, destinados a promover a realização de um determinado objetivo, implicam a restrição de direitos fundamentais e outros interesses constitucionalmente protegidos. A proporcionalidade atua como uma restrição às restrições e tem uma estrutura própria, sendo composta por três etapas

\footnotetext{
8 A utilização do exame de proporcionalidade nas relações entre particulares é controversa. No Brasil, Steinmetz (2004, p. 220ss) defende o recurso à proporcionalidade para analisar a admissibilidade de restrições a direitos fundamentais convencionadas entre indivíduos. Este entendimento, no entanto, é criticado por Silva (2005, p. 160ss), que argumenta que o recurso à proporcionalidade comprometeria significativamente a autonomia privada dos indivíduos que, diferentemente do Estado, não seriam obrigados a realizar os direitos fundamentais na maior medida possível.
} 
que obedecem a uma ordem pré-definida: adequação, necessidade e proporcionalidade em sentido estrito 9 . Cada uma dessas etapas é subsidiária à anterior, devendo ser realizada apenas se a medida cuja constitucionalidade é questionada tiver sido aprovada no exame anterior (SILVA, 2002, p. 34).

Ao contrário do que fazem crer algumas decisões judiciais e trabalhos acadêmicos, a proporcionalidade é uma ferramenta para o controle de medidas tomadas por outros agentes, e não uma técnica que auxilia os julgadores a encontrar decisões ótimas. Apesar de eventuais semelhanças, não deve haver confusão entre o exame de proporcionalidade em sentido estrito e o modelo de sopesamento de princípios proposto por Robert Alexy. ${ }^{10}$ Enquanto na colisão de princípios, o juízes têm o dever de aplicar a medida que promova os interesses colidentes na maior medida possível diante das circunstâncias do caso concreto, a eventual existência de alternativas que, no entendimento do Poder Judiciário, apresentem uma melhor relação promoção-restrição de direitos é absolutamente irrelevante para o resultado do exame de proporcionalidade.

O recurso à proporcionalidade na fundamentação das decisões de controle de constitucionalidade autoriza os órgãos judiciais a invalidar atos de outros poderes apenas em três hipóteses: (i) quando não promoverem a realização de nenhum interesse legítimo (adequação); (ii) quando forem mais restritivos do que alternativas igualmente ou mais eficazes (necessidade); (iii) quando a intensidade da restrição a direitos não puder ser justificada pelo peso concreto dos interesses promovidos (proporcionalidade em sentido estrito). Não há margem para declarar a inconstitucionalidade, nem para substituir a medida testada por possíveis alternativas mais restritivas, nem que promovam o interesse perseguido com menos intensidade, ainda que este déficit possa ser compensado pela realização muito maior de um princípio colidente (SIECKMANN, 2009, p. 103). ${ }^{11}$

\footnotetext{
${ }^{9}$ Há dois posicionamentos diversos quanto ao número de etapas do exame de proporcionalidade. Enquanto críticos do método do sopesamento, como Bodo Pieroth e Bernhard Schlink (2007, p. 6667), na Alemanha, e Dimitri Dimoulis e Leonardo Martins (2009, p. 229-230), no Brasil, defendem a supressão do exame de proporcionalidade em sentido estrito, alguns autores que analisam o uso da proporcionalidade pela Corte Européia de Direitos Humanos, como Jowell e Emiliou (1996, p. 115ss), defendem a existência de uma quarta etapa, a análise da legitimidade dos fins fomentados pela medida, que, como se verá a seguir, corresponde a uma parte do exame de adequação.

${ }^{10}$ Embora este não seja um trabalho sobre a teoria dos princípios, é importante destacar que, no âmbito da teoria proposta por Robert Alexy, os casos que ensejam a aplicação da proporcionalidade compreendem a antinomia entre uma regra e um princípio, e não entre princípios colidentes (LIMA, 2014).

${ }^{11}$ Nesse sentido, Robert Alexy (2014, p. 591) afirma que: "A máxima da necessidade é expressão da ideia de eficiência de Pareto. Em razão da existência de um meio que intervém menos e é igualmente adequado, uma posição pode ser melhorada sem que isso ocorra às custas da outra posição. É claro que, ao contrário do que ocorre com o exame da adequação, aqui não ocorre uma simples eliminação de meios. Mas ao legislador também não é prescrita categoricamente a adoção do meio que intervém em menor intensidade. O que se diz é apenas que, se o legislador quiser
} 
Embora seja fundamental para a compreensão e a aplicação correta do exame de proporcionalidade, esta característica é muitas vezes negligenciada por trabalhos acadêmicos e decisões judiciais. Quando isto acontece, o órgão que realiza o controle de constitucionalidade deixa de ser uma instância de revisão, encarregado de verificar a compatibilidade de um determinado ato normativo com a ordem constitucional e passa a atuar como uma nova instância decisória, ficando livre para substituir a medida adotada por órgãos estatais por aquela que considerar a forma mais correta ou conveniente de disciplinar uma determinada questão. Tendo em vista que juízes constitucionais podem controlar decisões de atores mais representativos ou detentores de maior competência técnica e instrumental, as consequências dessa mudança não são triviais e não devem ser subestimadas em uma ordem democrática.

É com o objetivo de evidenciar e evitar este problema que Alan Brady (2014, p. 11) caracteriza a proporcionalidade como um questionamento secundário endereçado a órgãos que controlam decisões de outros agentes -, e não como um questionamento primário - endereçado a quem deve regular uma matéria originariamente. Para Brady, um dos principais méritos da proporcionalidade consiste no fato de os questionamentos decorrentes de cada uma de suas etapas não se confundirem com os questionamentos enfrentados pelo órgão cuja atividade está sendo controlada. Assim, ao invés indagar se medida está correta ou é a mais conveniente, a proporcionalidade impõe ao Judiciário três questionamentos distintos, cujos parâmetros estão vinculados ao ato cuja constitucionalidade está sendo questionada.

Como análise da adequação exige apenas que a medida testada apenas fomente um objetivo legítimo - qualquer que seja ele, em qualquer intensidade possível - e o teste de necessidade impede que os patamares de realização dos princípios em jogo sejam sacrificados além do que estabelecidos pelo órgão que editou a medida questionada, ficam claras as limitações à discricionariedade dos juízes constitucionais. É importante atentar, ainda, que o teste de necessidade não envolve

\footnotetext{
perseguir o objetivo escolhido, ele pode adotar apenas o meio mais suave, ou um meio igualmente suave ou um meio ainda mais suave. Isso não é nenhuma otimização em direção a algum ponto máximo, mas apenas a vedação de sacrifícios desnecessários a direitos fundamentais". Em sentido contrário, alguns autores admitem alternativas menos eficazes ou mais gravosas, desde que eventuais déficits possam ser compensados pela promoção de princípios colidentes. É o caso de Rainer Dechsling (1989, p. 51-68), que propõe a substituição da otimalidade de Pareto pelo critério de eficiência de Kaldor-Hicks, e de Pieroth e Schlink (2007, p. 66-67) que entendem que o exame de proporcionalidade em sentido estrito deve ser evitado por meio de uma realização "mais criteriosa" do exame de necessidade, que seja capaz de justificar a revisão judicial de medidas que levariam a situações absurdas. A adoção da eficiência de Pareto em detrimento de alternativas que permitissem a compensação pode ser justificada pela função institucional que desempenha ao assegurar ao órgão que editou a medida cuja constitucionalidade é questionada a prerrogativa de definir o grau mínimo de realização tanto do objetivo promovido, como também do interesse cuja realização é restringida (LIMA, 2014, p. 98-111; RIVERS, 2006, p. 199).
} 
a comparação de medidas alternativas, mas consiste apenas numa análise de custo e benefício da medida em questão. Se a importância concreta da realização do interesse promovido justificar a intensidade da restrição provocada, a medida estará imune à revisão judicial. Caso contrário, ela deverá ser invalidada. ${ }^{12}$

Além de não poder substituir a medida testada por uma alternativa que promova a realização dos interesses em jogo com intensidade inferior à prevista pelo órgão que adotou regulamentação testada, o órgão judicial também não está obrigado a identificar uma medida que esteja apta a passar pelas três etapas da proporcionalidade. É plenamente possível, portanto, que não haja nenhuma alternativa que consiga promover o objetivo pretendido pela medida testada com intensidade suficiente para justificar a restrição aos demais direitos fundamentais. Se esse for o caso, deve-se simplesmente declarar a inconstitucionalidade da ação estatal. A proporcionalidade não oferece instrumentos para que juízes constitucionais supram eventuais lacunas, nem substituam órgãos legislativos e executivos na regulação da matéria. Sua função é evitar medidas desporporcionais ${ }^{13}, e$ não encontrar medidas ótimas

\section{Proporcionalidade E CULTURA DE JUSTIFICAÇão}

Considerando a estrutura da proporcionalidade e as limitações à argumentação judicial dela decorrentes, o que poderia justificar sua utilização por juízes e cortes constitucionais? Uma boa resposta para essa questão é a ideia de que o recurso à proporcionalidade na fundamentação das decisões de controle de constitucionalidade poderia fomentar o desenvolvimento de uma cultura de justificação da atividade estatal e, com isso, fortalecer as credenciais democráticas de um Estado.

Retomada por alguns trabalhos recentes sobre proporcionalidade, a ideia de cultura constitucional de justificação foi concebida originalmente por Etienne Mureinik, no contexto da constitucionalização sul-africana pós-Apartheid. O objetivo dessa tese, assim como de grande parte da trajetória profissional e política de Mureinik, era combater a "cultura constitucional de autoridade"14, que teria

12 Ao considerar apenas a medida testada e não todas eventuais alternativas, o exame de proporcionalidade em sentido estrito permite que se respeite a prerrogativa de estabelecer os patamares mínimos de realização dos princípios colidentes, que, como visto anteriormente, é conferida ao órgão que adotou a medida testada.

${ }^{13}$ No mesmo sentido Rivers (2006, p. 193).

${ }^{14}$ É importante esclarecer que uma cultura constitucional de autoridade não seria necessariamente autoritária ou não democrática, mas apenas uma cultura baseada na autoridade do governo para exercer o poder, na qual a legitimidade da ação governamental seria derivada de sua autoridade, e não do conteúdo de suas ações. Segundo David Dyzenhaus (1998, p. 33), “What Etienne called the culture of authority is a perverse neo-colonial version of the culture of reflection. For in its most powerful form, in the work of Jeremy Bentham, the idea of law as reflection works in the service of a radical democratic theory, in which statute law accurately reflect through the medium 
permitido o surgimento e a perpetuação de um regime de segregação racial no país. Ao discorrer sobre a transformação política e social que poderia ser desencadeada pela constituição-interina de 1993, ele afirmou que o documento deveria funcionar como uma ponte para uma cultura de justificação, na qual a legitimidade da ação estatal repousaria no apelo à defesa de suas decisões, e não no medo da força de seu comando. "A nova ordem deve ser uma comunidade construída com base no convencimento, e não na coerção." 15

Recorrendo à distinção entre cultura de autoridade e cultura de justificação, Moshe Cohen-Eliya e Iddo Porat sustentam que a difusão global da proporcionalidade, ocorrida nas últimas décadas, teria atendido a uma demanda internacional crescente pela mudança do paradigma de legitimidade do Estado, cuja atuação não mais poderia ser aceita apenas como uma forma de exercício de autoridade ${ }^{16}$, mas deveria ser justificada "nos termos de sua cogência e persuasão, isto é, de sua racionalidade e razoabilidade" (COHEN-ELIYA; PORAT, 2013, p. 112) Ainda que não consiga para explicar a difusão global da proporcionalidade, o trabalho de Cohen-Eliya e Porat fornece subsídios importantes para demonstrar que a tomada de decisão com base nessa técnica poderia ser benéfica para democracia constitucional.

Sem pretensão descritiva, Mattias $\operatorname{Kumm}$ (2007, p. 04) desenvolve com mais sucesso a tese de que o uso da proporcionalidade no controle de constitucionalidade poderia ser defendido, e não explicado, com base em suas consequências positivas para a promoção de uma cultura de justificação. Ele argumenta que cortes constitucionais deveriam promover uma espécie de "contestação socrática", isto é, deveriam enfrentar seus casos de maneira similar àquela que Sócrates teria utilizado para lidar com questões básicas sobre ética e justiça.

Na visão de Kumm, haveria uma grande semelhança entre a missão atribuída pelo Oráculo de Delfos ao pensador grego e a competência de guarda da

of the legislature the preferences of the majority. The judicial duty is to apply the law as it is and the citizens' duty is to obey the law as it is. (...) Such a legal culture, while one of authority and obedience, is far from authoritarian. (...) When, however, that culture is lifted from its democratic and legitimizing context and taken as a self-evident theory about how law works, it becomes highly authoritarian - as it did in South Africa".

15 "If the new constitution is a bridge away from a culture of authority, it is clear what it must be a bridge to. It must lead to a culture of justification - a culture in which the leadership given by government rests on the cogency of the case offered in defense of its decisions, not the fear inspired by the force at its command". (MUREINIK, 1994 p. 32).

${ }^{16}$ Para Cohen-Eliya e Porat (2013, p. 113) uma cultura de autoridade não excluiria a possibilidade de justificação das ações estatais. "However, in a culture of authority, justification for action is provided mainly at the stage of assigning authority, and once the authority has been assigned, the authorized body needs to offer little justification for its specific decisions. In contrast, in a culture of justification, even after authority has been assigned, the authorized body must still provide justification for all of its decisions". 
Constituição dos tribunais constitucionais. ${ }^{17}$ Convicto de que não conhecia nada além de sua própria ignorância, Sócrates teria cumprido o seu destino recorrendo ao elenchus, um método composto por uma série de questões encadeadas, cujo objetivo era testar a coerência de seus interlocutores. Ele não tinha a pretensão de defender as teses que considerava certas, mas desejava apenas compreender os motivos que levavam os demais cidadãos a crer que as suas opiniões eram corretas.

Tal como Sócrates, Kumm entende que as cortes constitucionais deveriam compelir autoridades públicas a defender as medidas que fossem impugnadas judicialmente, desencadeando um processo de engajamento argumentativo, que, resguardado por garantias institucionais e regras de independência judicial, não se confundiria com o jogo político ordinário. No âmbito dessa deliberação, não caberia aos juízes apontar as medidas que gostariam de adotar caso estivessem no lugar das autoridades questionadas, nem seria necessário que eles construíssem teorias elaboradas ou inovadoras. O papel desempenhado por eles deveria ser muito mais simples: após ouvir as considerações das partes e dos participantes do processo, caberia aos juízes apenas examinar se os argumentos apresentados pelos órgãos estatais seriam aceitáveis ou não.

Assim como o elenchus socrático, a proporcionalidade orientaria a interação entre juízes e demais participantes do processo, oferecendo uma estrutura para a avaliação de razões públicas (KUMM, 2012, p. 202-203). Partindo da premissa de que "a sabedoria específica de Sócrates e dos juízes constiucionais repousaria não no que eles sabem, mas nas questões que eles sabem fazer àqueles que têm, pelo menos prima facie, credenciais mais solidas para responder" (KUMM, 2007, p. 14), Kumm entende que o uso da proporcionalidade no controle de constitucionalidade poderia aumentar a qualidade das decisões tomadas por órgãos legislativos e executivos.

Ao compelir os agentes públicos a justificar suas decisões com argumentos sobre direitos e princípios constitucionais, o exame de proporcionalidade corrigiria eventuais vícios do processo político, diminuindo a incidência de decisões irrefletidas e medidas baseadas exclusivamente na tradição, em convenções sociais, tradições, ideologias ou interesses dominantes (KUMM, 2010, p. 142-175). Uma das principais vantagens da proporcionalidade consiste em canalizar os esforços de fundamentação judicial para o escrutínio de argumentos que possam ter legitimidade suficiente para justificar a restrição de direitos, ou seja, para argumentos sobre direitos fundamentais e princípios constitucionais (WEINRIB, 2006, p. 97).

Além de direcionar a argumentação para o que importa, outra vantagem da

\footnotetext{
${ }^{17}$ Assim como um artesão sem conhecimentos específicos sobre justiça ou tema correlatos teria sido considerado o homem mais sábio da Grécia, muitas constituições também atribuíram a competência de decidir em última instância sobre conflitos entre normas que expressam valores abertos e comportam múltiplas interpretações a indivíduos com formação jurídica, que teria de pouca valia para decidir sobre questões técnica e politicamente complexas.
} 
proporcionalidade seria sua maior simplicidade e transparência em relação a algumas alternativas mais tradicionais e já arraigadas na tradição jurídica de diversos países (CRAIG, 2010, p. 273) ${ }^{18}$. Em vez de construções dogmáticas herméticas e pouco compreensíveis para leigos, que comprometeriam a capacidade das cortes de arbitrar a razão pública, a tomada de decisão com base na proporcionalidade exigiria argumentações mais acessíveis ao público geral (KUMM, 2010, p. 155). Nas palavras de Mattias Kumm: "Ao aplicar a proporcionalidade, as cortes estão de fato avaliando se a legislação pode ou não ser justificada em termos de razões públicas, ou seja, de argumentos que possam ser aceitos racionalmente por todos os cidadãos, ainda que eles não o façam."19

A possibilidade de compreender a argumentação de juízes e cortes constitucionais sobre direitos fundamentais e garantias previstas na Constituição é um elemento central para a associação da proporcionalidade com a atuação das cortes constitucionais como instâncias de justificação da atividade estatal. Para que a proporcionalidade possa cumprir algum papel no fortalecimento da legitimidade democrática de uma corte constitucional, é indispensável que os juízos apresentados em cada uma das suas três etapas sejam fundamentados. Não basta, portanto, que se declare que o ato questionado promove ou não um interesse legítimo, que há ou não uma alternativa menos restritiva e pelo menos tão eficaz, nem que a restrição a direitos provocada pelo ato questionado não pode ou não ser justificada pela realização de outros princípios. Juízes e cortes constitucionais devem sustentar esses juízos com argumentos que possam ser compreendidos por terceiros - e isso restringe significativamente sua ingerência sobre os demais órgãos estatais.

Embora este seja um ponto pouco destacado na literatura sobre o tema, sobretudo no Brasil, deve ficar claro que, em face dos limites da compreensão e da comunicação, nem sempre juízes e cortes constitucionais chegarão a uma resposta precisa e definitiva para o exame de proporcionalidade. É provável que em algumas situações, sobretudo nas etapas da necessidade e da proporcionalidade em sentido estrito, não se possa fundamentar a precedência de um dos princípios

\footnotetext{
${ }^{18}$ Stone-Sweet e Matthews (2011, p. 699-785) consideram a simplicidade dessa estrutura como uma das razões para a difusão internacional da proporcionalidade.

${ }_{19}$ Para Kumm (2010, p. 168-169): “The outcome must plausibly qualify as a collective judgment of reason about what the commitment to rights of citizens translates into under the concrete circumstances addressed by the legislation. Even if it is not necessary for everyone to actually agree with the results, the result must be justifiable in terms that those who disagree with it might reasonably accept. It must be morally plausible to imagine even those addressees most burdened by a law to have hypothetically consented to it. Even those left worst of and most heavily burdened by legislation must be conceivable as free and equal partners in a joint enterprise of law-giving. Those burdened by legislation must be able to see themselves not only as losers of a political battle dominated by the victorious side (ah, the spoils of victory!), they must be able to interpret the legislative act as a reasonable attempt to specify what citizens - all citizens, including those on the losing side-owe to each other as free and equals."
} 
colidentes em relação ao outro ou garantir que não haja nenhuma alternativa menos gravosa e pelo menos tão eficiente. Incertezas epistêmicas existem e juízes não estão imunes a elas. Diante de prognósticos incertos e desacordos razoáveis, não é possível, com base na estrutura do exame de proporcionalidade, declarar a inconstitucionalidade da medida cuja constitucionalidade é questionada. ${ }^{20}$

Ao reformar decisões de outros Poderes sem demonstrar com argumentos passíveis de controle de intersubjetivo porque elas seriam injustificáveis, cortes constitucionais não poderiam ser consideradas como elementos catalizadores de uma cultura de justificação. Para que possam reforçar a obediência às decisões estatais com base nos seus fundamentos, e não apenas na força de sua autoridade, as decisões de controle judicial de constitucionalidade não devem estar condicionadas apenas às preferências dos juízes constitucionais. Numa cultura de justificação, a legitimidade da atuação contra-majoritátia das cortes constitucionais depende da possibilidade de justificação de suas ações perante a população, ou seja, da demonstração de que não há fundamentos racionais e legítimos para atuação estatal. ${ }^{21}$

\section{A PROPORCIONALIDADE NA CULTURA DE PERSUASÃo}

A tese de que o uso da proporcionalidade poderia promover uma cultura constitucional de justificação tem caráter normativo, e não descritivo. Ou seja: não explica o fenômeno de difusão internacional da proporcionalidade, tampouco reflete o que se pratica em qualquer corte ou tribunal, seja ele brasileiro, inglês ou alemão. Embora pareça trivial, essa observação se faz necessária. Alguns trabalhos sobre tema, sobretudo os críticos à proporcionalidade e ao sopesamento de princípios, têm ignorado essa importante distinção e condenado concepções teóricas com base em objeções a decisões judiciais que as invocam ou que teriam

\footnotetext{
${ }^{20}$ No âmbito da teoria dos princípios, este tema é tratado pela dogmática dos âmbitos de discricionariedade (ALEXY, 2014, p. 575-627).

${ }^{21}$ Isto é exposto de forma clara por Kumm (2010, p. 168-169), "When courts apply the proportionality test, they are in fact assessing whether or not legislation can be justified in terms of public reasons[...]. When such a justification succeeds a court is in fact saying something like the following to the rights-claiming litigant: What public authorities have done, using the legally prescribed democratic procedures, is to provide a good faith collective judgment of reason about what justice and good policy requires under the circumstances. Given the fact of reasonable disagreement on the issue and the corollary margin of appreciation/deference that courts appropriately accord electorally accountable political institutions under the circumstances, it remains a possibility that public authorities were wrong and you are right and that public authorities should have acted otherwise. But our institutional role as a court is not to guarantee that public authorities have found the one right answer to the questions they have addressed. Our task is to police the boundaries of the reasonable and to strike down as violations of right those acts of public authorities that, when scrutinized, cannot plausibly be justified in terms of public reason. Conversely, a court that strikes down a piece of legislation on the grounds that it violates a right is in fact telling public authorities and the constituencies who supported the measure: Our job is not to govern and generally tell public authorities what justice and good policy requires. But it is our job to detect and strike down as instances of legislated injustice measures that, whether supported by majorities or not, impose burdens on some people, when no sufficiently plausible defense in terms of public reasons can be mounted for doing so".
} 
pretendido aplicá-las (ÁVILA, 2009; NEVES, 2013). A prática da proporcionalidade nem sempre é igual ao discurso sobre a proporcionalidade. E, no caso específico do Supremo Tribunal Federal, a distância entre discurso e prática é grande.

Em primeiro lugar, é importante atentar ao papel que a proporcionalidade deveria cumprir na fundamentação da decisão. Para que possa fomentar a atuação de cortes como instâncias de justificação da atividade estatal, a proporcionalidade e suas três etapas ordenadas e subsidiárias devem estruturar a decisão, orientando a avaliação dos argumentos apresentados para impugnar ou justificar o ato cuja constitucionalidade é objeto da decisão. Ao contrário do que ocorre na Alemanha, este tipo de prática, como já foi apontado, é rara por aqui (SILVA, 2002; CAMARGO, 2009, p. 37-52).

Em geral, quando decide sobre a constitucionalidade de uma medida que restringe direitos fundamentais, o Tribunal Constitucional Federal tende a orientar a fundamentação de suas decisões com base nas sub-regras deste exame, procurando demonstrar com diversos argumentos se uma determinada medida estatal promove um interesse legítimo, (ii) se há uma alternativa menos gravosa capaz de fazê-lo com no mínimo a mesma intensidade e (iii) se a intensidade da restrição imposta pela medida pode ser justificada pela importância do interesse promovido. Para responder a cada uma dessas indagações, considerações de diferentes naturezas, que abrangem desde questões fáticas, que podem demandar a consulta de informações técnicos ou a oitiva de especialistas, até precedentes judiciais e aspectos da dogmática jurídica, são articuladas em um esforço de justificação que, em geral, se estende por várias páginas e corresponde a uma parcela extremamente significativa da fundamentação da decisão. Como as divergências são pouco frequentes e as posições convergentes de diferentes juízes são consolidadas em um voto único, é possível dizer que o exame de proporcionalidade tem um papel decisivo na construção da decisão que a corte alemã apresenta ao público.

O cenário é completamente distinto no Supremo Tribunal Federal. Em primeiro lugar, porque os votos dos onze membros desse tribunal são publicados individualmente, independentemente de suas orientações. Divergências são muito mais frequentes do que na corte alemã e o grau de coesão e diálogo entre os votos é extremamente reduzido ${ }^{22}$. Devido a fatores culturais e à forma de deliberação na

\footnotetext{
${ }^{22}$ Para que a comparação com o Tribunal Constitucional Federal Alemão possa fazer sentido, essa afirmação leva em conta o comportamento do tribunal nos principais casos de controle de constitucionalidade, e não em todas as decisões, que em sua absoluta maioria são unânimes ou monocráticas. É importante destacar que a competência do Supremo Tribunal Federal (STF) não se restringe ao controle judicial de constitucionalidade. Além de atuar como um órgão de cúpula judicial, com a tarefa de uniformizar a interpretação das normas constitucionais no Brasil, o STF também possui uma ampla competência originária e recursal, sobretudo em matéria penal e administrativa. Diante disso, da extensão territorial e demográfica do Brasil e de uma cultura jurídica centrada na judicialização de conflitos, a carga processual do tribunal é gigantesca. No ano de 2015, por exemplo, foram proferidas 116.669 decisões pelo STF, sendo 98.917 monocráticas e 17.752 colegiadas. Tendo em vista que a corte é composta por onze juízes, é natural que a maioria dessas inúmeras decisões sejam coesas e livres de dissenso.
} 
corte - que, além de ser televisionada em tempo real, não comporta reuniões fechadas entre os juízes e é marcada pela leitura de longos votos previamente preparados - são raros os momentos em que os ministros interagem visando à construção de uma fundamentação comum e consistente (SILVA, 2013, p. 567-584). É comum, sobretudo em julgamentos de grande visibilidade, que cada ministro apresente uma peça autônoma e autossuficiente e a decisão do tribunal é determinada fundamentalmente pela agregação das partes dispositivas dos votos. Quando mais de seis ministros considerarem uma medida incompatível com a constituição, ela deverá ser declarada inconstitucional, ainda que não seja possível identificar uma ratio decidendi ou fundamento comum, ainda que majoritário, para essa decisão. Essas características tendem a reduzir consideravelmente a importância do exame de proporcionalidade na formação da decisão da corte brasileira, pois são raras as situações em que dois ou mais juízes recorrem a uma mesma linha de argumentação.

Além disso, em geral, o exame de proporcionalidade não cumpre um papel decisivo nem mesmo nos votos individuais. Ao contrário do que ocorre na Alemanha, no Brasil o exame de proporcionalidade não costuma ser utilizado para estruturar a argumentação judicial. Na maioria das vezes, a proporcionalidade funciona apenas como um argumento que é somado a uma série de outras considerações, nem sempre compatíveis. Ao invés de desencadear um esforço de justificação, a proporcionalidade acaba sendo invocada pelos juízes brasileiros para aliviar o ônus de fundamentação das suas decisões. Em geral, cita-se um autor ou tribunal estrangeiro discorrendo sobre a estrutura do exame de proporcionalidade, para logo em seguida concluir, sem a devida fundamentação, que a medida é adequada, necessária e proporcional em sentido estrito, o que corrobora a sua manutenção, ou que ela não passa por algum desses testes (geralmente, pelos três) e deve ser rejeitada.

A decisão proferida no HC 82.424, conhecido como Caso Ellwanger, ilustra de forma muito significativa os problemas mencionados acima. Apontado pelo próprio Supremo Tribunal Federal como um dos julgamentos mais importantes da sua história, o caso girava em torno da prescritibilidade do crime pelo qual Siegfried Ellwanger, escritor e sócio de uma editora que publicava obras com conteúdo antissemita, havia sido condenado. Em linhas gerais, se a discriminação contra judeus fosse considerada racismo, a perda de pretensão punitiva do Estado não afetaria o caso, uma vez que nos termos do art. 5ㅇ, XLII, da Constituição Federal, a prática do racismo constitui crime imprescritível. De acordo com o pedido formulado no habeas corpus, caso a conduta fosse enquadrada em qualquer outra hipótese prevista no art. 20 da Lei 7.716/89, como a discriminação por religião, etnia ou procedência nacional, o crime estaria prescrito.

Diante do que foi apresentado até aqui, deveria causar estranhamento o uso da proporcionalidade neste caso. Por mais complexo ou significativo que fosse o caso em julgamento, a questão central consistia na dúvida quanto à qualificação do 
antissemitismo como racismo ou, de outra forma, na distinção entre o racismo e outros tipos de condutas discriminatórias. Não se tratava, portanto, de avaliar se medidas que restringem direitos e princípios constitucionais poderiam ser justificadas em face de outros valores constitucionalmente protegidos - o que seria o cenário típico de aplicação da técnica da proporcionalidade. Ainda que a maioria dos ministros tenha se manifestado sobre a constitucionalidade da criminalização do discurso antissemita, é importante destacar que o próprio relator original do caso, Min. Moreira Alves, não seguiu essa orientação e dedicou o seu voto essencialmente ao alcance da imprescritibilidade do crime de racismo, tendo concluído pela extinção da punibilidade do crime cometido por Ellwanger. Dos onze votos proferidos, apenas dois recorreram à proporcionalidade: os dos Ministros Marco Aurélio e Gilmar Mendes.

Embora possa chamar atenção o fato de esses dois votos terem chegado a conclusões diametralmente opostas, é importante esclarecer que a divergência quanto ao resultado da análise da proporcionalidade não indicaria, por si só, uma deficiência dessa técnica de argumentação, nem um problema na sua aplicação. Como a proporcionalidade apenas estrutura o processo de argumentação por meio de questionamentos ordenados e pré-definidos, é plenamente possível que juízes diferentes cheguem a conclusões distintas para cada uma de suas etapas, sobretudo quando não há precedentes judiciais ou outros elementos autoritativos que possam orientar a fundamentação dos votos. Uma das vantagens da proporcionalidade está justamente na facilidade que ela oferece para a focalização de eventuais de divergências entre membros de órgãos colegiados, o que, por outro lado, viabiliza a identificação de posições consensuais. Não foi isso, no entanto, o que se observou no julgamento do Caso Ellwanger.

No teste de adequação, o Ministro Marco Aurélio entendeu, de um lado, que caberia "indagar se condenar o paciente e proibi-lo de publicar os pensamentos, aprender e destruir as obras editadas são os meios adequados para acabar com a discriminação contra o povo judeu ou com o risco de se incitar a discriminação" (BRASIL, 2003 a, p. 40). A conclusão, fundamentada em dois parágrafos, foi negativa, pois, na visão do Ministro, o pensamento de Ellwanger, embora preconceituoso em relação aos judeus, não teria potencial discriminatório, uma vez que não estimularia terceiros a "separar, apartar, segregar, sem que haja fundamento para tanto" (BRASIL, 2003 a, p. 40). Por outro lado, após longas considerações teóricas sobre o princípio da proporcionalidade e sua aplicação pelo Supremo Tribunal Federal, o Min. Gilmar Mendes sustentou, em poucas linhas, que seria "evidente a adequação da condenação do paciente para se alcançar o fim almejado, qual seja, a salvaguarda de uma sociedade pluralista, onde reine a tolerância" (BRASIL, 2003 b, p. 33).

O tom categórico e a fundamentação escassa também são observados na aplicação do teste de necessidade. Nenhum dos ministros procedeu à comparação das alternativas possíveis e, embora tenham chegado a conclusões opostas - o que 
não é um problema - cada considerou que o seu entendimento seria "a única solução cabível". Sem utilizar como parâmetro a criminalização do discurso discriminatório, que era a medida testada, o Ministro Marco Aurélio sustentou, em poucas linhas, que "a observância desse subprincípio deixa ao Tribunal apenas uma solução cabível, ante a impossibilidade de aplicar outro meio menos gravoso ao paciente: conceder a ordem, garantindo o direito à liberdade de manifestação do pensamento, preservados os livros, já que a restrição a tal direito não garantirá, sequer a conservação da dignidade do povo judeu" (BRASIL, 2003 a, p. 41) Igualmente sucinto, o Min. Gilmar Mendes afirmou o contrário e, tomando o preceito constitucional que considera o racismo um crime imprescritível, conclui que a medida seria necessária, pois "dificilmente vai se encontrar um meio menos gravoso a partir da própria definição constitucional. [...] Não se trata aqui sequer de obras revisionistas da história, mas de divulgação de ideias que atentam contra a dignidade dos judeus" (BRASIL, 2003 b, p. 34).

Por fim, na análise da proporcionalidade em sentido estrito, o Min. Marco Aurélio conclui que a condenação de Ellwanger não seria razoável, pois haveria "outras maneiras mais fáceis, rápidas e econômicas de a população ter acesso a tais pensamentos, como a internet" (BRASIL, 2003 a, p. 42). Na visão do Ministro, a publicação de diversos outros livros com conteúdo discriminatório ou racista inclusive de autores renomados como Nina Rodrigues, Gilberto Freyre e José Bonifácio de Andrada e Silva - evidenciaria o descabimento da medida em análise, uma vez que não caberia ao Poder Judiciário "exterminar essas fontes de conhecimento do cenário nacional” (BRASIL, 2003 a, p. 43). Em sentido contrário, o Min. Gilmar Mendes foi novamente sucinto. Após afirmar que a liberdade de expressão teria "caráter inexcedível para o sistema democrático", ele concluiu seu voto de forma categórica:

“Todavia, é inegável que essa liberdade não alcança a intolerância racial e o estímulo à violência, tal como afirmado no acórdão condenatório. Há inúmeros outros bens jurídicos de base constitucional que estariam sacrificados na hipótese de se dar uma amplitude absoluta, intangível, à liberdade de expressão em espécie. Assim, a análise da bem fundamentada decisão condenatória evidencia que não restou violada a proporcionalidade" (BRASIL, 2003 b, p. 34-35)

A despeito das conclusões completamente antagônicas, merece destaque o fato de os Ministros Gilmar Mendes e Marco Aurélio terem recorrido a expedientes bastante semelhantes: invocaram a proporcionalidade nas páginas finais de seus votos; justificaram seu uso com considerações teóricas e citações de autores alemães; sustentaram de maneira extremamente parcial, eloquente e sintética que a condenação atacada no habeas corpus mereceria o mesmo juízo diante dos testes de adequação, necessidade e proporcionalidade em sentido. Embora se tratasse de um caso controverso e complexo - cujo julgamento comportou quatro pedidos de vista e resultou num acórdão, marcado por de debates, de incríveis 488 páginas -, 
em momento algum os Ministros mostraram-se permeáveis a argumentos que pudessem contrariar a parte dispositiva de seus votos.

Os questionamentos impostos pelas três etapas da proporcionalidade - se a criminalização de livros com conteúdo antissemita (i) promoveria a realização de algum objetivo legítimo, (ii) se haveria formas menos restritivas de fazê-lo de modo, no mínimo, igualmente e (iii) se a restrição aos direitos fundamentais decorrentes dessa medida seriam compensada pela promoção de outros interesses constitucionalmente protegidos - não foram enfrentados de forma clara nos votos. Apesar de ter sido invocada pelos dois ministros, com digressões sobre sua estrutura e suas sub-regras, a proporcionalidade não impôs aos julgadores qualquer ônus argumentativo. Seu papel foi essencialmente ornamental, a exemplo do que ocorreu com as citações de teóricos estrangeiros que a precederam. Ao invés expor de forma clara e organizada os diferentes argumentos baseados em direitos fundamentais que foram levados à corte pelos atores envolvidos no processo, o uso da proporcionalidade nos dois votos apenas conferiu uma aparência mais sofisticada e pretensamente erudita à posição defendida por cada Ministro.

Esse uso meramente retórico ou ornamental da proporcionalidade não guarda nenhuma semelhança com a ideia de promoção uma cultura constitucional de justificação, que poderia justificar o uso dessa técnica nas decisões de controle de constitucionalidade. Como tem sido frequentemente observado na atuação do Supremo Tribunal Federal, os Ministros procuraram convencer a opinião pública ou os seus pares a qualquer custo, escolhendo razões ou linhas argumentativas de forma estratégica. ${ }^{23}$ Isso explica uma série de inconsistências na aplicação da proporcionalidade observada nos dois votos, como a não identificação clara da medida cuja constitucionalidade seria questionada, a inexistência de qualquer comparação entre medidas alternativas na análise de necessidade, bem como a não realização de uma análise de custo e benefícios em relação aos direitos restringidos e promovidos no teste da proporcionalidade em sentido estrito. Assumindo que o intuito dos ministros seria o de validar suas posições sobre a prisão de Siegfried Ellwanger, não faria sentido, portanto, abrir flancos para considerações que poderiam enfraquecer seus posicionamentos individuais.

O desejo de fortalecer um voto pela concessão do habeas corpus permite que se compreenda, por exemplo, o fato de o Ministro Marco Aurélio não ter respeitado o caráter subsidiário das três etapas da proporcionalidade e encerrado sua análise

\footnotetext{
${ }^{23}$ Este tipo de postura é comum no Supremo Tribunal Federal, cujos juízes, segundo Virgílio Afonso da Silva (2013, p. 577), têm o hábito de argumentar como advogados, não como juízes. "The justices in the Brazilian Supreme Court do not see it as their task to disclose as much information as possible. In order to convince their colleagues (or an external audience) they tend to adopt strategies that are similar to those of lawyers. Among other things, this means that, when advocating for a given thesis or solution in a case, they do not feel compelled to reveal information that runs contrary to their arguments. Just as lawyers often cite only academic works and judicial precedents that corroborate their interests, the justices in the Brazilian Supreme Court frequently do the same".
} 
após a reprovação no teste da adequação. Afinal, se a medida restritiva não fomentava a realização de nenhum interesse legítimo, uma vez que o conteúdo dos livros editados por Ellwanger não seria discriminatório, qual seria o sentido que questionar se haveria uma alternativa menos restritiva para atingir a mesma finalidade? Não há hipótese lógica de uma medida reprovada no teste de adequação ser bem-sucedida nas etapas seguintes da proporcionalidade. Apesar de trivial, este problema pode ser encontrado em outros votos e decisões do Supremo, para além do caso Ellwanger. Em decisão mais recente, por exemplo, ao analisar a proporcionalidade da criminalização do aborto no Brasil, o Ministro Luís Roberto Barroso estruturou o seu voto com base na proporcionalidade e também entendeu que a medida deveria ser reprovada nas três etapas do teste (BRASIL, 2016).

$\mathrm{Na}$ jurisprudência do Supremo Tribunal Federal, a proporcionalidade é, portanto, uma ideia fora de lugar. Não visa ao escrutínio argumentativo da atividade estatal, mas sim à validação da posição defendida por um Ministro e ao aumento do seu poder de persuasão sobre seus pares, a comunidade jurídica e a opinião pública. Ao contrário do que propõe Mattias Kumm, não há por aqui qualquer pretensão de contestação socrática no controle judicial de constitucionalidade, com a consideração estruturada de argumentos divergentes trazidos pelas partes, amici curiae e outros ministros. ${ }^{24}$ Embora os testes de

${ }^{24}$ Diferentemente de Sócrates, que pressupunha sua própria ignorância, os integrantes do Supremo

Tribunal Federal consideram-se, em suas próprias palavras, parte de uma "vanguarda iluminista", tão ou mais legítima do que os demais Poderes para inovar na ordem jurídica, na medida em que representariam a população argumentando, e não decidindo. A tese da vanguarda iluminista é de Luís Roberto Barroso (2015, p. 42). Já a ideia de representação argumentativa tem como a base o pensamento de Robert Alexy (1999, p. 66). Em mais de uma oportunidade, o Min. Gilmar Mendes invocou a citação de Alexy: "O parlamento representa o cidadão politicamente, o tribunal constitucional argumentativamente" (BRASIL, 2008, p. 466 e 467; 2011, p. 142). Na ADI 3510, que tratava constitucionalidade das pesquisas com células-tronco embrionárias humanas, a uma citação foi utilizada para responder a questionamentos sobre uma intervenção excessiva do Supremo Tribunal Federal no âmbito de atuação do Poder Legislativo. Por meio da ideia de representação argumentativa da jurisdição constitucional, o Min. Mendes procurou justificar seu voto, que, dentre a imposição de outras condicionantes controversas, determinava a criação de comitê nacional centralizado com composição multidisciplinar para controle ético das pesquisas, que não fora previsto pela legislação questionada, nem mencionado por nenhum dos diversos atores sociais que participaram do processo. Já no julgamento da ADPF 132, na qual se pleiteava a proteção jurídica às uniões homoafetivas, a ideia de representação argumentativa foi invocada como um argumento para autorizar o tribunal a superar a literalidade do texto constitucional brasileiro, que, em seu artigo 226, § 3, estabelece que: "Para efeito da proteção do Estado, é reconhecida a união estável entre o homem e a mulher como entidade familiar, devendo a lei facilitar sua conversão em casamento". Embora uma crítica detalhada a esta interpretação da ideia de representatividade argumentativa transcenda o escopo deste artigo, convém destacar que a representação argumentativa ou discursiva que seria desempenhada pelos órgãos judiciais só existiria enquanto suas decisões pudessem ser justificadas com argumentos juridicamente válidos, 
necessidade e de proporcionalidade em sentido estrito exijam expressamente que se avalie a importância dos interesses promovidos e restringidos pelas medidas, ao recorrer a essa técnicas os juízes brasileiros, em geral, abordam exclusivamente os aspectos favoráveis à sua posição - como foi visto no caso Ellwanger. O recurso à proporcionalidade não visa ao escrutínio argumentativo da atividade estatal, mas é parte de uma estratégia argumentativa que visa a aumentar o poder de convencimento das posições defendidas por cada ministro.

\section{CONSIDERAÇÕES FINAIS}

O caminho tortuoso na recepção do exame de proporcionalidade não parece ser uma exclusividade brasileira. No Reino Unido, houve uma certa dificuldade para assimilar a estrutura dessa técnica de argumentação e conciliá-la com outros testes de razoabilidade vigentes, o que despertou, em um primeiro momento, reações controvertidas tanto na literatura jurídica, como também na própria jurisprudência a respeito da sua utilização no controle de medidas estatais. Mesmo em decisões emblemáticas para a difusão internacional da proporcionalidade ${ }^{25}$, como as proferidas pela Suprema Corte do Canadá no caso R v Oakes (CANADÁ, 1986) e pela Corte Constitucional da África do Sul no caso S v Makwanyane and Another (ÁFRICA DO SUL, 1995), é possível notar uma certa dificuldade na aplicação dessa técnica. Apesar de definir os parâmetros que passariam a ser utilizados para controlar restrições a direitos fundamentais em seus respectivos países, as duas decisões são marcadas por longas considerações sobre o exame de proporcionalidade e seu tratamento no direito estrangeiro que, a despeito de sua importância para casos futuros, são irrelevantes para a solução dos problemas em questão ${ }^{26}$.

isto é, com base em normas jurídicas, precedentes judiciais e demais constrangimentos autoritativos de um sistema jurídico, que sejam orientados por regras de racionalidade prática que possibilitem o controle intersubjetivo. Caberia, portanto, à jurisdição constitucional definir as fronteiras do que é discursivamente possível. A tomada de decisão nesse âmbito seria de competência dos Poderes Executivo e Legislativo, que investidos por meio do sufrágio eleitoral seriam incumbidos da representação volitiva ou decisionista da população (ALEXY, 2005, p. 572-581; 2014, p. 197-209).

25 Segundo Kai Möller (2012, p. 14), essas decisões marcam a recepção do exame de proporcionalidade em seus respectivos países.

${ }^{26}$ Os dois casos foram resolvidos por meio da subsunção, e não do sopesamento ou da proporcionalidade. No caso R v Oakes, a Suprema Corte Canadense considerou que inversão do ônus da prova nos delitos de tráfico de drogas violava a garantia da presunção de inocência, enquanto no caso S v Makwanyane and Another, a Corte Constitucional da África do Sul invalidou uma condenação à pena de morte, por considerá-la incompatível com a regra constitucional que proibia punições cruéis, desumanas e degradantes. 
Embora possam parecer muito distantes, as perspectivas de melhora no caso brasileiro dependeriam necessariamente de uma mudança na forma como os Ministros compreendem o seu papel institucional. Para que uma corte possa atuar como uma instância de justificação é fundamental que seus integrantes queiram assumir essa função. Este é um pré-requisito para que a fundamentação das decisões de controle de constitucionalidade seja levada a sério e encarada como parte essencial do exercício da jurisdição constitucional. O reconhecimento de que a corte deveria atuar como uma instância de justificação tornaria mais legítima e consistente a exigência de que os ministros argumentassem de forma clara, coerente e honesta, enfrentando de forma transparente argumentos contrários, precedentes judiciais, enunciados normativos e eventuais dúvidas, incertezas empíricas e epistêmicas. Esse cenário é pressuposto para que a proporcionalidade - ou qualquer outra técnica de argumentação - possa fortalecer as credenciais democráticas de uma corte constitucional.

Ao concluir o ensaio do qual foi extraída a epígrafe deste trabalho, Roberto Schwarz (2014, p. 64) afirma que, diante da reprodução de ideias fora de lugar, o romancista brasileiro que tem como matéria as grandes questões da história mundial "não as trata, se as tratar diretamente". Guardadas as devidas proporções, procurei demonstrar neste trabalho que criticar a forma com que a proporcionalidade foi apropriada e vem sendo reproduzida de forma imprópria no direito brasileiro, não fazendo jus aos pretensos benefícios que teriam legitimado sua concepção e difusão internacional, não deve ser encarada como uma tarefa criticamente ingênua de "censor[es] do uso correto da terminologia construída a partir de um modelo teórico"(NEVES, 2019, p. 308). Voltando à lição sempre oportuna de Schwarz, ideias europeias (e estrangeiras) são incansavelmente reproduzidas em sentido impróprio no Brasil. Não há como tratá-las como matéria e problema da literatura ou do direito quando não se percebe que elas estão fora de lugar. A causa dos problemas por aqui observados podem não estar nas ideias em si, mas nas condições de sua apropriação e na sua reprodução em sentido impróprio.

\section{REFERÊNCIAS}

ÁFRICA DO SUL. CCT3/94) [1995] ZACC 3; 1995 (6) BCLR 665; 1995 (3) SA, 1995.

ALEXY, Robert. Balancing, Constitutional Review and Representation.

International Journal of Constitutional Law, v. 3, 2005.

ALEXY, Robert. Constitutional Rights, Democracy and Representation. Richerche Giuridiche, v. 3, 2014, p. 197-209. 
ALEXY, Robert. Direitos Fundamentais no Estado constitucional Democrático: Para a relação entre direitos do homem, direitos fundamentais, democracia e jurisdição constitucional. Revista de Direito Administrativo, v. 217, 1999.

ALEXY, Robert. Teoria dos Direitos Fundamentais. 2. Ed. São Paulo: Malheiros, 2014.

ÁVILA, Humberto. Neoconstitucionalismo: entre a 'ciência do Direito' e o 'Direito da Ciência. Revista Eletrônica de Direito do Estado, v. 17, 2009.

BARROSO, Luís Roberto. A razão sem voto: o Supremo Tribunal Federal e o governo da maioria. Revista Brasileira de Políticas Públicas, v. 5, 2015.

BOROWSKI, Martin. Grundrechte als Prinzipien. 2. Ed. Baden-Baden: Nomos, 2007.

BRADY, Alan D. P. Proportionality and Deference under the UK Human Rights Act: An Institutionally Sensitive Approach. New York: Cambridge University Press, 2014.

BRASIL.Supremo Tribunal Federal, HC 82.424, Rel. Min. Moreira Alves, voto Min. Marco Aurélio, j. 17/09/2003 a.

BRASIL. Supremo Tribunal Federal, HC 82.424, Rel. Min. Moreira Alves, voto Min. Gilmar Mendes, j. 17/09/2003 b.

BRASIL. Supremo Tribunal Federal, ADI 3.510, Rel. Min. Ayres Britto, voto Min. Gilmar Mendes, j. 19/05/2008.

BRASIL. Supremo Tribunal Federal, ADPF 132, Rel. Min. Ayres Britto, j. 05/05/2011.

BRASIL. Lei no 13.105/2015.

BRASIL. Supremo Tribunal Federal, HC 124.306, Rel. Min. Marco Aurelio, j. 09/08/2016.

CAMARGO, Manuela Oliveira. Proporcionalidade e razoabilidade na jurisprudência do STF: os casos de conflito de princípios da ordem econômica. In: 
COUTINHO, Diogo R. e VOJVODIC, Adriana M. Jurisprudência Constitucional: como decide o STF? São Paulo: Malheiros, 2009.

CANADÁ. R v Oakes (1986) I SCR.

CLÉRICO, Laura. Die Struktur der Verhältnismäßigkeit. Baden-Baden: Nomos, 2001.

CLÉRICO, Laura. Hacía la reconstrucción de un modelo integrado de proporcionalidad a la luz de la jurisprudencia de la Corte Interamericana de Derechos Humanos. In: CAPALDO, Griselda, SIECKMANN, Jan, CLÉRICO, Laura. Internacionalización del Derecho Constitucional, Constitucionalización del Derecho Internacional. Buenos Aires: Eudeba, 2012.

COHEN-ELYA, Moshe, PORAT, Iddo. American Balancing and German Proportionality: The historical origins. International Journal of Constitutional Law, v. 8, 2010.

COHEN-ELYA, Moshe, PORAT, Iddo. Proportionality and Constitutional Culture. Cambridge: Cambridge University Press, 2013.

DECHSLING, Rainer. Das Verhältnismäßigkeitsgebot: Eine Bestandaufnahme der Literatur zur Verhältnismßßigkeit staatlichen Handels. Munique: Vahlen, 1989.

DYZENHHAUS, David. Law as Justification: Etienne Mureinik's Conception of Legal Culture. South African Journal of Human Rights, v. 14, 1998.

EMILIOU, Nicholas. The Principle of Proportionality in European Law. Londres: Kluwer Law Internation, 1996.

HUSCROFT, Grant, MILLER, Bradley, WEBER, Grégoire. Proportionality and the Rule of Law: Rights, Justification, Reasoning. Cambridge: Cambridge University Press, 2014.

JOWELL, Jeffrey. Beyond the Rule of Law: Towards Constitutional Judicial Review. Public Law, v. 4, 2000. 
KAVANAGH, Aileen. Constitutional Review under the UK Human Rights Act. Cambridge: Cambridge University Press, 2009.

KUMM, Mattias. Institutionalising Socratic Contestation: The Rationalist Human Rights Paradigm, Legitimate Authority and the Point of Judicial Review.

European Journal of Legal Studies, v. 1, 2007.

KUMM, Mattias. Alexy's Theory of Constitutional Rights and the Problem of Judicial Review. In: KLATT, Matthias (ed.). Institutionalized Reason: The Jurisprudence of Robert Alexy. Oxford: Oxford University Press, 2012.

KUMM, Mattias. The Idea of Socratic Contestation and the Right to Justification: The Point of Rights-Based Proportionality Review. Law \& Ethics of Human Rights, v. 4, n. 2, 2010.

LIMA, Rafael Bellem de. Regras na Teoria dos Princípios. São Paulo: Malheiros, 2014.

MARTINS, Leonardo; DIMOULIS, Dimitri. Teoria Geral dos Direitos

Fundamentais. 2 ed. São Paulo: Revista dos Tribunais, 2009.

MÖLLER, Kai. The Global Model of Constitutional Rights. Oxford: Oxford University Press, 2012.

MÖLLER, Kai. From constitutional to human rights: On the moral structure of international human rights. Global Constitutionalism, v. 3, 2014.

MUREINIK, Etienne. A bridge to where? Introducing the Interim Bill of Rights. South African Journal of Human Rights, v. 10, 1994.

NEVES, Marcelo. Entre Hidra e Hércules: Princípios e Regras Constitucionais. São Paulo: Martins Fontes, 2013.

NEVES, Marcelo. O Profeta, os Discípulos e o "Enviado": Comentários a Virgílio Afonso da Silva. Revista Estudos Institucionais, v. 5, 2019.

PIEROTH, Bodo; SCHLINK, Bernhard. Grundrechte: Staatsrecht II. 23. ed. Heidelberg: C.F. Müller, 2007. 
RIVERS, Julian. Proportionality and variable intensity of Review. Cambridge Law Journal, v. 65, 2006.

SCHAUER, Frederick. Freedom of Expression Adjudication in Europe and America: A Case Study in Comparative Constitutional Architecture. In: NOLTE, Georg. European and US Constitutionalism. Cambridge: Cambridge University Press, 2005.

SCHWARZ, Roberto. As Ideias fora do lugar: Ensaios selecionados. São Paulo: Penguin Classics - Companhia das Letras, 2014.

SIECKMANN, Jan. Balancing, Optimisation, and Alexy's "Weight Formula". ARSP Beiheft, v. 124, 2009.

SILVA, Virgílio Afonso da. O proporcional e o razoável. Revista dos Tribunais, v. 798, 2002.

SILVA, Virgílio Afonso da. A Constitucionalização do Direito: Os direitos fundamentais nas relações entre particulares. São Paulo: Malheiros: 2005.

SILVA, Virgílio Afonso da. Deciding without deliberating. International Journal of Constitutional Law, v. 11, 2013.

STEINMETZ, Wilson. A vinculação dos particulares a direitos fundamentais. São Paulo, Malheiros: 2004.

STONE-SWEET, Alec; MATTHEWS, Jud. All things in proportion? American Rights Review and the Problem of Balancing. Emory Law Journal, v. 60, 2011.

STONE-SWEET, Alec; MATTHEWS, Jud. Proportionality, Judicial Review, and Global Constitutionalism. In: SARTOR, G., VALENTINI, C. (eds).

Reasonableness and Law. Law and Philosophy Library, v. 86. Dordrecht: Springer: 2009.

WEINRIB, Lorraine E. The postwar paradigm and American exceptionalism. In: CHOUDHRY, Sujit. The Migration of Constitutional Ideas. New York: Cambridge University Press, 2006. 